\section{Avaliação da implantação da resposta à emergência de saúde pública de microcefalia no Estado de Pernambuco, Brasil}

\author{
Evaluation of implementation of the response to \\ the public health emergency of microcephaly in \\ Pernambuco State, Brazil
}

\section{Evaluación de la implantación de la respuesta a la emergencia de salud pública por microcefalia \\ en el Estado de Pernambuco, Brasil}

\section{Resumo}

Este estudo teve por objetivo avaliar o grau de implantação da resposta à emergência da microcefalia associada ao vírus Zika em Pernambuco, Brasil. Trata-se de um estudo avaliativo normativo realizado no epicentro inicial da emergência em saúde pública internacional, ocorrida entre outubro de 2015 e julho de 2017. Elaborou-se um modelo lógico da intervenção sob análise, contendo os componentes Gestão, Vigilância e Assistência em suas dimensões de estrutura, processo e resultado, a partir de publicações técnicas e normativas institucionais, além de uma matriz de indicadores correspondente para julgamento. Coletaram-se dados a partir da aplicação de questionário, observação direta e consulta a documentos oficiais. Os resultados mostraram implantação parcial $(74,9 \%)$ da resposta à emergência de microcefalia pela Secretaria Estadual de Saúde, com a dimensão processo atingindo 75\% do esperado, e a estrutura, 74,5\%. A Vigilância foi o único componente avaliado como implantado (81\%), ainda que com carência de investimentos regionais e laboratorial, e a Gestão $(74,2 \%)$ e a Assistência (68,8\%), parcialmente implantadas, com insuficiências nos quesitos referentes a recursos humanos e estrutura física, planejamento e avaliação. Conclui-se que o grau de implantação da resposta à emergência em saúde pública internacional de microcefalia associada ao vírus Zika foi avaliado como implantação parcial, com diferentes níveis entre os componentes da intervenção, sobressaindo-se a Vigilância em comparação à Gestão e Assistência. As inconformidades sinalizam a necessidade de investimentos para o enfrentamento de futuras emergências em saúde pública, com vistas a intervenções mais oportunas e adequadas.

Avaliação em Saúde; Planos de Emergência; Microcefalia
Lucilene Rafael Aguiar 1

Paulo Germano de Frias 2

Louisiana Regadas de Macedo Quinino 3

Democrito de Barros Miranda-Filho 1

doi: 10.1590/0102-311X00271020

\author{
Correspondência \\ L. R. Aguiar \\ Programa de Pós-graduação em Ciências da Saúde, \\ Universidade de Pernambuco, Recife, Brasil. \\ Rua Prudente de Moraes 569, Recife, PE 52041-725, Brasil. \\ lucilene.rafael@upe.br

\footnotetext{
1 Programa de Pós-graduação em Ciências da Saúde, Universidade de Pernambuco, Recife, Brasil.

2 Instituto de Medicina Integral Professor Fernando Figueira, Recife, Brasil.

3 Centro de Pesquisas Aggeu Magalhães, Fundação Oswaldo Cruz, Recife, Brasil.
} 


\section{Introdução}

As respostas às emergências são um problema para a saúde pública que impactam a vida cotidiana das pessoas com repercussões tangíveis e intangíveis, locais, nacionais e internacionais 1,2. As políticas governamentais norteadas pela publicação do Regulamento Sanitário Internacional (RSI), revisado em 2005, estabeleceram critérios definidores de emergência em saúde pública. A Organização Mundial da Saúde (OMS), desde então, reconheceu seis eventos de emergência em saúde pública de importância internacional: em 2009, a pandemia de influenza A (H1N1); em 2014, a poliomielite selvagem e o Ebola; em 2016, a expansão de casos de infecção pelo vírus Zika (ZIKV); em 2018, o surto de Ebola; e, em 2020 3, a pandemia de COVID-19. No Brasil, um dos mais recentes episódios teve seu início em 2015, detectado a partir do aumento de casos de microcefalia neonatal 4,5,6.

A situação epidemiológica da transmissão do ZIKV chamou a atenção global quando, em outubro de 2015, o aumento do número de recém-nascidos com microcefalia foi detectado no Estado de Pernambuco, Brasil 7 . O estado, além de ter sido o primeiro a detectar as alterações do padrão epidemiológico, esteve entre as Unidades Federadas que apresentaram as maiores prevalências ${ }^{8}$, concentração de casos notificados e confirmados de microcefalia 9 . Diante dessa situação inusitada, o Ministério da Saúde, em novembro de 2015, declarou uma possível relação entre a epidemia de microcefalia e a infecção pelo ZIKV durante a gravidez, com base no acúmulo de evidências 10.

A resposta brasileira à emergência em saúde pública constituiu um desafio para a o Sistema Único de Saúde (SUS), ainda que este seja universal, descentralizado e de gestão interfederativa com responsabilidades partilhadas entre União, estados e municípios. À esfera estadual compete a prestação de serviços de média e alta complexidade organizados de forma hierarquizada e regionalizada 11.

No período entre 2015 e 2017, Pernambuco registrou 2.508 casos suspeitos de síndrome congênita do Zika vírus (SCZV), dos quais 467 (18,6\%) foram confirmados, 1.835 (73,2\%) descartados, 106 $(4,2 \%)$ inconclusivos e $100(4 \%)$ permaneciam em investigação 12 . A garantia de acesso à saúde no sistema público cresceu em relevância ao se constatar que a emergência da microcefalia atingiu na sua maioria a população periférica, pobre e negra, cuja condição vulnerável demanda maior dependência do amparo governamental 13 .

O alto número de notificações e o desconhecimento inicial da etiologia da microcefalia requereram a definição de ações, o estabelecimento de protocolos em campo e a tomada de decisão, apesar do conhecimento científico insuficiente e impreciso ${ }^{8}$. Durante a emergência em saúde pública da microcefalia, importantes avanços científicos foram constatados sobre a SCZV, principalmente no que concerne a estudos epidemiológicos e clínicos 8 . Contudo, permanecem lacunas, em particular as relacionadas à avaliação da resposta governamental à emergência em saúde pública. Perduram as necessidades de estudos sobre resposta às emergências, com abordagens que fundamentem a organização dos serviços e a tomada de decisão, de forma a fomentar o aprimoramento para futuras intervenções 14 .

Considerando a relevância da resposta dada à epidemia e de sua contribuição à organização operacional do SUS, este estudo teve por objetivo avaliar o grau de implantação da resposta à emergência da microcefalia associada ao ZIKV ocorrida em Pernambuco no período de 2015-2017.

\section{Método}

\section{Desenho e área do estudo}

Estudo avaliativo normativo, a partir de abordagem sistêmica para verificar se os recursos e processos da resposta à emergência de microcefalia, em Pernambuco, no período entre outubro de 2015 e julho de 2017, foram adotados de acordo com as normas da resposta à emergência em saúde pública 15.

Pernambuco localiza-se na Região Nordeste, conta com 184 municípios, além do distrito de Fernando de Noronha. É o sétimo estado mais populoso do país, predominantemente urbano (80\%), com índice de desenvolvimento humano (IDH) de 0,673 e rendimento domiciliar per capita mensal de cerca de USD 228. Conta com rede assistencial instalada com 57 hospitais distribuídos em quatro macrorregiões de saúde. Tem serviços de vigilância descentralizados em 12 Gerências Regionais de Saúde 
(Geres) e conta com o Centro de Informações Estratégico de Vigilância em Saúde (Cievs) instalado no nível central do estado e na capital 16.

\section{Etapas do processo avaliativo}

\section{- Etapa 1 - elaboração do modelo lógico da intervenção}

Construiu-se um esquema visual para apresentar como a resposta à emergência de microcefalia deveria ser implantada e os resultados esperados. Buscou-se compreender a intervenção no estado, envolvendo as ações realizadas pelo nível central da Secretaria de Saúde e por suas extensões regionais, bem como as intrincadas relações entre seus componentes com base em publicações técnicas e normativas da OMS 17, Ministério da Saúde 18,19 e Secretaria de Saúde de Pernambuco 20,21,22.

A expressão do encadeamento lógico da resposta à emergência da microcefalia associada ao ZIKV foi decomposta em três componentes: Gestão, Vigilância e Assistência, com as respectivas dimensões de estrutura, processo e resultados (Figura 1). A dimensão estrutura foi avaliada a partir dos recursos físicos, humanos, financeiros, materiais, normativos e equipamentos. $\mathrm{Na}$ dimensão processo, o componente Gestão foi avaliado considerando comando operacional, planejamento, monitoramento e avaliação, comunicação de risco e pesquisa. Na Vigilância, foram verificados os aspectos relaciona-

\section{Figura 1}

Modelo lógico da resposta à emergência da microcefalia associada ao vírus Zika. Pernambuco, Brasil, $2015-2017$.

COMPONENTE ESTRUTURA

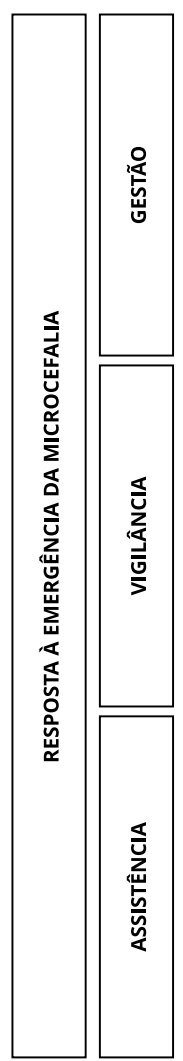

PROCESSOS

- Estabelecimento de situação de emergências em saúde pública

- Constituição de comando operacional

- Realização de planejamento

- Monitoramento das atividades

- Estabelecimento da avaliação

- Organização da comunicação de risco

- Instituição de parceria para realização de pesquisa

- Detecção e notificação dos casos suspeitos

- Implantação das investigações estruturadas

- Realização da análise de dados

- Produção e divulgação de informações

- Adoção de medidas de controle e prevenção

Instituição da assistência integral à gestante com exantema

- Instituição da assistência integral à criança com SCZV

\begin{tabular}{|l|l|}
\multicolumn{1}{c|}{\begin{tabular}{c}
\multicolumn{1}{c|}{ RESULTADO } \\
(Imediatos/Intermediários)
\end{tabular}} \\
\begin{tabular}{|l|l|}
\hline - Emergência em saúde pública \\
regulamentada
\end{tabular} \\
- Estrutura pública ordenada à \\
emergência em saúde pública \\
- Gestão integrada entre instâncias \\
governamentais e não \\
governamentais
\end{tabular}


dos a detecção/notificação, investigação, análise de dados e divulgação de informações e medidas de controle e prevenção. Na Assistência, foi averiguado o cuidado à gestante com exantema e à criança com SCZV. A dimensão resultados foi descrita no modelo para expressar o caminho até o impacto esperado da resposta à emergência de microcefalia.

\section{- Etapa 2 - elaboração da matriz de indicadores e julgamento}

A partir do modelo lógico, foi construída uma matriz de indicadores e julgamento representativa das dimensões de estrutura e processo de cada componente utilizado para o cálculo do grau de implantação (GI) da resposta à emergência de microcefalia (Quadro 1). Para conferir validade de conteúdo e o constructo da intervenção, foi utilizada técnica de consenso organizada em três fases: (1) avaliação e preenchimento do modelo lógico e matriz de indicadores previamente elaborados pelos pesquisadores; (2) discussão aberta entre os participantes; (3) resposta individual às questões propostas. Participaram do consenso sete especialistas provenientes do serviço e da academia com experiência em avaliação e/ou emergência em saúde pública. Os parâmetros de julgamento foram definidos com base em normativas institucionais para a resposta às emergência em saúde pública e, na sua ausência, foram arbitrados empiricamente a partir do consenso com especialistas.

Foram utilizados dados primários obtidos mediante preenchimento de questionário, como também observação direta pelos pesquisadores de aspectos estruturais e processuais nos níveis central e regional da Secretaria de Saúde de Pernambuco. Dados secundários foram extraídos de documentos oficiais disponíveis nos portais: http://www.cievspe.com e http://www.saude.pe.gov.br. O instrumento para coleta de dados foi elaborado com base na matriz de indicadores, organizada por componente e dimensão avaliada. Foram realizados ajustes a partir de piloto em que se aplicou o questionário a cinco profissionais de saúde envolvidos com a emergência em saúde pública.

Os participantes foram selecionados por comporem os principais grupos envolvidos no processo decisório de políticas públicas e de implementação das ações da emergência (informantes-chave). Responderam ao questionário 28 profissionais: seis gestores, 13 técnicos do nível central, dois técnicos do laboratório de saúde pública e sete técnicos das Geres.

Os indicadores da matriz receberam pontuação de acordo com sua importância para a resposta à emergência. A pontuação máxima para cada dimensão (estrutura e processo) foi 100, a qual foi distribuída de forma semelhante entre os três componentes, a partir da média de pontos atribuída pelos especialistas na técnica de consenso: Gestão (31), Vigilância (36) e Assistência (33) (Quadro 1).

\section{- Etapa 3 - definição do grau de implantação}

Para julgar o GI da resposta do estado à emergência e de cada um dos seus componentes, procedeuse aos seguintes passos: (1) verificou-se o percentual de adequação dos dados empíricos observados em relação aos esperados explicitados na matriz de indicadores; (2) atribuiu-se peso três à dimensão estrutura (E) e peso sete à dimensão processo $(\mathrm{P})$, a partir de definição do consenso com os especialistas, de modo que o total possível de ser atingido foi de 100 pontos, obedecendo à seguinte fórmula: $\mathrm{GI}=(\mathrm{Ex} 3+\mathrm{Px} 7): 10$. Baseado nisso, o GI foi classificado em: implantado $=80 \%-100 \%$; parcial $=$ $60 \%-79,9 \%$; incipiente $=40 \%-59,9 \%$ e não implantado $<40 \%$, arbitrados pelos autores com base em estudos prévios 23 .

\section{Aspectos éticos}

Esta pesquisa foi aprovada pelo Comitê de Ética e Pesquisa do Complexo do Hospital Universitário Oswaldo Cruz e do Pronto Socorro Cardiológico de Pernambuco (HUOC/Procape, com CAAE 64419417.1.0000.5192). Aqueles que concordaram em participar do estudo assinaram o termo de consentimento livre e esclarecido, e a identidade deles foi preservada. 


\section{Quadro 1}

Matriz de indicadores do grau de implantação (GI) da resposta à emergência da microcefalia. Pernambuco, Brasil, 2015-2017.

\begin{tabular}{|c|c|c|c|c|}
\hline \multicolumn{2}{|c|}{ COMPONENTE/DIMENSÃO } & \multirow{2}{*}{$\begin{array}{l}\text { INDICADORES } \\
\text { Recursos humanos }\end{array}$} & \multirow[t]{2}{*}{ PONTUAÇÃO } & \multirow[t]{2}{*}{$\begin{array}{l}\text { PONTUAÇÃO MÁXIMA/ } \\
\text { ALCANÇADA }\end{array}$} \\
\hline \multirow[t]{33}{*}{ Gestão } & \multirow[t]{20}{*}{ Estrutura } & & & \\
\hline & & $\begin{array}{l}\text { Gestores experientes e capacitados para emergência em } \\
\text { saúde pública }\end{array}$ & 1 por item & $2,0 / 2,0$ \\
\hline & & $\begin{array}{l}\text { Existência de assessoria: epidemiológica, científica, imprensa, } \\
\text { financeira }\end{array}$ & 1 por item & $4,0 / 3,0$ \\
\hline & & Dimensionamento técnico suficiente (nível central e regional) & 1 por item & $2,0 / 0,0$ \\
\hline & & $\begin{array}{l}\text { Flexibilidade para realocação e contratação de recursos } \\
\text { humanos }\end{array}$ & 1 por item & $2,0 / 2,0$ \\
\hline & & Recursos financeiros & & \\
\hline & & Existência de orçamento para emergência em saúde pública & $0=$ Não; 2 = Sim & $2,0 / 0,0$ \\
\hline & & Existência de orçamento para pesquisa & $0=$ Não; 2 = Sim & $2,0 / 2,0$ \\
\hline & & Existência de recursos de outras fontes: interna e externa & 2 por item & $4,0 / 4,0$ \\
\hline & & Recursos materiais & & \\
\hline & & Disponibilidade de material de escritório & 0 = Não; 1 = Sim & $1,0 / 1,0$ \\
\hline & & Estrutura física & & \\
\hline & & Disponibilidade de estrutura para instalação do COES & 0 = Não; $2=S i m$ & $2,0 / 2,0$ \\
\hline & & Normativas & & \\
\hline & & $\begin{array}{l}\text { Existência de Decreto de emergência em saúde pública pelo } \\
\text { Poder Executivo estadual. }\end{array}$ & $0=$ Não; 1 = Sim & $1,0 / 1,0$ \\
\hline & & $\begin{array}{l}\text { Existência de Plano Estadual de Resposta à emergência em } \\
\text { saúde pública }\end{array}$ & $0=$ Não; 1 = Sim & $1,0 / 1,0$ \\
\hline & & $\begin{array}{l}\text { Existência de planos de contingência: gestão, vigilância, } \\
\text { assistência, comunicação de risco e pesquisa }\end{array}$ & 1 por item & $5,0 / 2,0$ \\
\hline & & Equipamentos & & \\
\hline & & Disponibilidade de equipamentos & 1 por item & $3,0 / 3,0$ \\
\hline & & Pontuação da estrutura da gestão & & $31,0 / 23,0$ \\
\hline & \multirow[t]{13}{*}{ Processo } & Comando operacional & & \\
\hline & & $\begin{array}{l}\text { Constituição do COES, equipe operacional (gerência e líderes, } \\
\text { gestores na linha de comando), equipe consultiva (técnicos e } \\
\text { especialistas locais e interinstitucionais }\end{array}$ & 1 por item & $6,0 / 5,0$ \\
\hline & & Articulação intergovernamental & $0=$ Não; $1=\operatorname{Sim}$ & $1,0 / 1,0$ \\
\hline & & Planejamento, monitoramento e avaliação & & \\
\hline & & $\begin{array}{l}\text { Realização de planejamento (estratégico, tático e } \\
\text { operacional), monitoramento e avaliação (inicial, final e nível } \\
\text { de atenção da emergência) }\end{array}$ & 1 por cada item & $7,0 / 3,0$ \\
\hline & & Comunicação de risco & & \\
\hline & & $\begin{array}{l}\text { Realização de busca ativa de rumores, campanha de } \\
\text { mobilização social e produção de informes }\end{array}$ & 1 por cada item & $3,0 / 3,0$ \\
\hline & & $\begin{array}{l}\text { Estabelecimento de portais para informações e produções } \\
\text { técnicas, porta-voz e ouvidoria }\end{array}$ & 1 por cada item & $4,0 / 3,0$ \\
\hline & & Pesquisa & & \\
\hline & & $\begin{array}{l}\text { Instituição de interlocutor, cooperação técnica } \\
\text { interinstitucional (local, nacional e internacional) e ações } \\
\text { integradas de vigilância e assistência }\end{array}$ & 1 por item & $6,0 / 5,0$ \\
\hline & & $\begin{array}{l}\text { Incorporação de achados científicos no planejamento das } \\
\text { ações }\end{array}$ & 0 = Não; 1 = Sim & $1,0 / 1,0$ \\
\hline & & $\begin{array}{l}\text { Produção de publicações técnicas e científicas pela área } \\
\text { de vigilância, assistência e em parceria com institutos de } \\
\text { pesquisa }\end{array}$ & 1 por item & $3,0 / 2,0$ \\
\hline & & Pontuação do processo da gestão & & $31,0 / 23,0$ \\
\hline
\end{tabular}


Quadro 1 (continuação)

\begin{tabular}{|c|c|c|c|c|}
\hline \multicolumn{2}{|c|}{ COMPONENTE/DIMENSÃO } & \multirow{2}{*}{$\begin{array}{l}\text { INDICADORES } \\
\text { Recursos humanos }\end{array}$} & \multirow[t]{2}{*}{ PONTUAÇÃO } & \multirow{2}{*}{$\begin{array}{l}\text { PONTUAÇÃO MÁXIMA/ } \\
\text { ALCANÇADA }\end{array}$} \\
\hline \multirow[t]{21}{*}{ Vigilância } & \multirow[t]{21}{*}{ Estrutura } & & & \\
\hline & & $\begin{array}{l}\text { Experiente, capacitado e com equipe de investigação de } \\
\text { campo }\end{array}$ & 1 por item & $3,0 / 3,0$ \\
\hline & & $\begin{array}{l}\text { Equipe Cievs suficiente, permanência > } 2 \text { anos, vínculo } \\
\text { estável e com ponto nas regionais }\end{array}$ & 1 por item & $4,0 / 2,0$ \\
\hline & & Equipe suficiente no nível central, Lacen e Regional & 1 por item & $3,0 / 2,0$ \\
\hline & & $\begin{array}{l}\text { Rotina de treinamentos simulados de emergência em saúde } \\
\text { pública }\end{array}$ & $0=$ Não; $1=\operatorname{Sim}$ & $1,0 / 0,0$ \\
\hline & & $\begin{array}{l}\text { Equipe capacitada para vigilância da SCZV e gestante com } \\
\text { exantema }\end{array}$ & 1 por item & $2,0 / 2,0$ \\
\hline & & Recursos financeiros & & \\
\hline & & Existência de recursos para ações de vigilância & $0=$ Não; $2=\operatorname{Sim}$ & $2,0 / 2,0$ \\
\hline & & Recursos materiais & & \\
\hline & & $\begin{array}{l}\text { Disponibilidade de reagentes (dengue, Zika, chikungunya, } \\
\text { rubéola, herpes, sífilis e citomegalovírus) e insumo } \\
\text { laboratorial }\end{array}$ & 0,5 por item & $4,0 / 3,0$ \\
\hline & & $\begin{array}{l}\text { Disponibilidade de kit para controle vetorial e insumo de } \\
\text { prevenção }\end{array}$ & 1 por item & $2,0 / 2,0$ \\
\hline & & Estrutura física & & \\
\hline & & Instalações adequadas no nível central, Lacen e regional & 1 por item & $3,0 / 2,0$ \\
\hline & & Existência de SVO & $0=\mathrm{Não} ; 1=\operatorname{Sim}$ & $1,0 / 1,0$ \\
\hline & & Normativas & & \\
\hline & & $\begin{array}{l}\text { Existência prévia de portaria de implantação do Cievs, } \\
\text { Portaria de DNC, Instrumento de avaliação de risco, Plano de } \\
\text { contingência para arbovírus }\end{array}$ & 1 por item & $4,0 / 4,0$ \\
\hline & & Existência de protocolo e informes epidemiológicos & 1 por item & $2,0 / 2,0$ \\
\hline & & Equipamentos & & \\
\hline & & $\begin{array}{l}\text { Disponibilidade no Cievs de equipamento de informática, } \\
\text { comunicação, ferramentas de análise estatística e } \\
\text { geoprocessamento e no Lacen de sistema de informação, } \\
\text { equipamento para análise de amostra clínica }\end{array}$ & 0,5 por item & $3,0 / 2,5$ \\
\hline & & Disponibilidade de equipamento para controle vetorial & 0 = Não; 2 = Sim & $2,0 / 2,0$ \\
\hline & & Pontuação da estrutura da vigilância & & $36,0 / 29,5$ \\
\hline
\end{tabular}

(continua) 
Quadro 1 (continuação)

\begin{tabular}{|c|c|c|c|c|}
\hline \multicolumn{2}{|c|}{ COMPONENTE/DIMENSÃO } & \multirow{2}{*}{$\begin{array}{l}\text { INDICADORES } \\
\text { Detecção/Notificação }\end{array}$} & \multirow[t]{2}{*}{ PONTUAÇÃO } & \multirow{2}{*}{$\begin{array}{c}\text { PONTUAÇÃO MÁXIMA/ } \\
\text { ALCANÇADA }\end{array}$} \\
\hline \multirow[t]{23}{*}{ Vigilância } & \multirow[t]{23}{*}{ Processo } & & & \\
\hline & & Notificação oportuna ao nível hierárquico superior & 0 = Não; 1 = Sim & $1,0 / 1,0$ \\
\hline & & $\begin{array}{l}\text { Estabelecimento de notificação: imediata - casos suspeitos } \\
\text { de SCZV e gestante com exantema; mediata - notificação } \\
\text { negativa de casos. }\end{array}$ & 1 por item & $3,0 / 2,0$ \\
\hline & & Estabelecimento da vigilância da SCZV & $0=\mathrm{Não} ; 2=\operatorname{Sim}$ & $2,0 / 2,0$ \\
\hline & & Elaboração de formulário eletrônico para notificação & $0=$ Não; $1=\operatorname{Sim}$ & $1,0 / 1,0$ \\
\hline & & Realização de busca ativa hospitalar & $0=$ Não; $1=\operatorname{Sim}$ & $1,0 / 1,0$ \\
\hline & & Investigação & & \\
\hline & & Monitorização das gestantes com exantema & $0=$ Não; 2 = Sim & $2,0 / 0,0$ \\
\hline & & $\%$ de casos notificados para SCZV encerrados ( $\geq 90 \%$ ) & 0,5 por ano & $1,5 / 1,0$ \\
\hline & & $\begin{array}{l}\text { \% de casos suspeitos testados laboratorialmente para SCZV } \\
\text { (pelo menos 10\%) }\end{array}$ & 0,5 por ano & $1,5 / 0,5$ \\
\hline & & $\begin{array}{l}\text { Descentralização da investigação para os níveis regional e } \\
\text { municipal }\end{array}$ & 1 por item & $2,0 / 2,0$ \\
\hline & & $\begin{array}{l}\text { Participação das áreas técnicas nas investigações, comitês e } \\
\text { apoio às SMS }\end{array}$ & 0,5 por item & $1,5 / 1,5$ \\
\hline & & $\begin{array}{l}\text { Implantação do diagnóstico laboratorial para ZIKV (RT-PCR, } \\
\text { Elisa, Mac-Elisa, PRNT, anatomopatológico, histopatológico e } \\
\text { imuno-histoquímico) e celeridade no registro e emissão dos } \\
\text { laudos pelo Lacen }\end{array}$ & 0,5 por item & $4,5 / 2,5$ \\
\hline & & Pactuação de novas referências laboratoriais & $0=$ Não; $2=\operatorname{Sim}$ & $2,0 / 2,0$ \\
\hline & & Realização do diagnóstico diferencial para STORCH & $\begin{array}{l}0=\text { Não; } 0,5 \text { = Parcial } ; \\
1 \text { = Pleno }\end{array}$ & $1,0 / 0,5$ \\
\hline & & Análise de dados e divulgação de informações & & \\
\hline & & Realização de análise de dados & $0=$ Não; 2 = Sim & $2,0 / 2,0$ \\
\hline & & Estabelecimento de periodicidade de análise dos dados & $0=$ Não; $2=\operatorname{Sim}$ & $2,0 / 2,0$ \\
\hline & & Elaboração e divulgação de informes epidemiológicos & 2 por item & $4,0 / 4,0$ \\
\hline & & Medidas de controle e prevenção & & \\
\hline & & Apoio aos municípios nas ações de controle vetorial & $0=$ Não; $2=\operatorname{Sim}$ & $\begin{array}{l}2,0 / 2,0 \\
2,0 / 20\end{array}$ \\
\hline & & $\begin{array}{l}\text { Implementação de controle de hemoderivados e órgãos para } \\
\text { transplante. }\end{array}$ & 1 por item & \\
\hline & & Pontuação do processo da vigilância & & $36,0 / 29,0$ \\
\hline
\end{tabular}

(continua) 
Quadro 1 (continuação)

\begin{tabular}{|c|c|c|c|c|}
\hline \multicolumn{2}{|c|}{ COMPONENTE/DIMENSÃO } & \multirow{2}{*}{$\begin{array}{l}\text { INDICADORES } \\
\text { Recursos humanos }\end{array}$} & \multirow[t]{2}{*}{ PONTUAÇÃO } & \multirow{2}{*}{$\begin{array}{l}\text { PONTUAÇÃO MÁXIMA/ } \\
\text { ALCANÇADA }\end{array}$} \\
\hline \multirow[t]{30}{*}{ Assistência } & \multirow[t]{17}{*}{ Estrutura } & & & \\
\hline & & $\begin{array}{l}\text { Gestão experiente e preparada para emergência em saúde } \\
\text { pública }\end{array}$ & 1 por item & $2,0 / 0,0$ \\
\hline & & Equipes assistenciais engajadas e suficientes & 1 por item & $2,0 / 1,0$ \\
\hline & & $\begin{array}{l}\text { Equipe capacitada para atendimento à criança com SCZV e à } \\
\text { gestante com exantema }\end{array}$ & 1,5 por item & $3,0 / 3,0$ \\
\hline & & Recursos financeiros & & \\
\hline & & Existência de recursos para ações assistência & $0=$ Não; 2 = Sim & $2,0 / 2,0$ \\
\hline & & Recursos materiais & & \\
\hline & & Existência de medicamentos essenciais & $0=$ Não; $2=\operatorname{Sim}$ & $2,0 / 2,0$ \\
\hline & & Estrutura física & & \\
\hline & & $\begin{array}{l}\text { Existência de serviços de referência (assistência } \\
\text { especializada, diagnóstico de imagem e reabilitação) }\end{array}$ & 2 por item & $6,0 / 6,0$ \\
\hline & & Existência de serviços de referência nas macrorregionais & 1 por macrorregião & $4,0 / 1,0$ \\
\hline & & $\begin{array}{l}\text { Existência de Centros Especializados em Reabilitação nas } \\
\text { macrorregiões }\end{array}$ & 1 por macrorregião & $4,0 / 1,0$ \\
\hline & & Normativas & & \\
\hline & & Existência de protocolos e notas técnicas & 2 por item & $4,0 / 4,0$ \\
\hline & & Equipamentos & & \\
\hline & & $\begin{array}{l}\text { Disponibilização de equipamentos para diagnóstico e } \\
\text { reabilitação }\end{array}$ & 2 por item & $4,0 / 2,0$ \\
\hline & & Pontuação da estrutura da assistência & & $33,0 / 22,0$ \\
\hline & \multirow[t]{13}{*}{ Processo } & Cuidado à gestante com exantema & & \\
\hline & & $\begin{array}{l}\text { Elaboração de parâmetros de avaliação clínico-diagnóstica e } \\
\text { fluxograma de atenção }\end{array}$ & 2 por item & $4,0 / 4,0$ \\
\hline & & $\begin{array}{l}\text { Celeridade na implantação de serviços assistenciais de } \\
\text { referência e na descentralização para as macrorregiões }\end{array}$ & 1 por item & $2,0 / 0,0$ \\
\hline & & Estabelecimento da regulação do atendimento & $0=$ Não $2=\operatorname{Sim}$ & $2,0 / 2,0$ \\
\hline & & Realização do monitoramento e avaliação assistencial & 1 por item & $2,0 / 0,0$ \\
\hline & & Cuidado à criança com SCZV & & \\
\hline & & $\begin{array}{l}\text { Elaboração de parâmetros de avaliação clínica e diagnóstico } \\
\text { e fluxograma de atenção }\end{array}$ & 2 por item & $4,0 / 4,0$ \\
\hline & & $\begin{array}{l}\text { Implantação oportuna de serviços assistenciais essenciais de } \\
\text { referência e na descentralização para as macrorregiões }\end{array}$ & 2 por item & $4,0 / 2,0$ \\
\hline & & Regulação do atendimento e mutirões assistenciais & 2 por item & $4,0 / 4,0$ \\
\hline & & $\begin{array}{l}\text { Habilitação de Centros Especializados em Reabilitação nas } \\
\text { macrorregiões }\end{array}$ & $0=$ Não $2=\operatorname{Sim}$ & $2,0 / 0,0$ \\
\hline & & Fornecimento de medicamento & $0=$ Não $2=\operatorname{Sim}$ & $1,0 / 1,0$ \\
\hline & & $\begin{array}{l}\text { Realização de monitoramento, avaliação das ações de } \\
\text { assistência, apoio à família e articulação com assistência } \\
\text { social }\end{array}$ & 2 por item & $8,0 / 6,0$ \\
\hline & & Pontuação do processo da assistência & & $33,0 / 23,0$ \\
\hline \multirow{2}{*}{\multicolumn{2}{|c|}{ GERAL }} & Pontuação total da estrutura & & $100,0 / 74,5$ \\
\hline & & Pontuação total do processo & & $100,0 / 75,0$ \\
\hline
\end{tabular}

Cievs: Centro de Informações Estratégicas de Vigilância em Saúde; COES: Centro de Operações de Emergência em Saúde; DNC: doença de notificação compulsória; Lacen: Laboratório de Saúde Pública; SCZV: síndrome congênita do Zika vírus; SMS: Secretaria Municipal de Saúde; STORCH: infecção congênita por sífilis, toxoplasmose, rubéola, citomegalovírus e herpes; SVO: Serviço de verificação de óbito; ZIKV: vírus Zika. 


\section{Resultados}

A implantação da resposta da Secretaria de Saúde de Pernambuco à emergência de microcefalia foi avaliada como parcial (74,9\%), sendo o componente Vigilância o único considerado implantado (81\%). Os componentes Gestão $(74,2 \%)$ e Assistência (68,8\%) foram classificados como implantação parcial. As dimensões estrutura e processo obtiveram avaliação semelhante, com 74,5\% e 75\%, ambas classificadas como tendo implantação parcial (Tabela 1)

O componente Gestão, nas dimensões estrutura e processo, foi classificado como implantação parcial. Na estrutura, o menor valor obtido diz respeito às normativas $(57,1 \%)$, avaliada como implantação incipiente pela inexistência de Plano Estadual de resposta a emergência em saúde pública. Os recursos humanos (70\%) e financeiros $(75 \%)$ tiveram implantação parcial pelo contingente limitado de técnicos nos níveis central e regional e pela inexistência de orçamento prévio para emergência em saúde pública, respectivamente. Estrutura física, recursos materiais e equipamentos foram avaliados como implantados, com pontuação plena de $100 \%$. Na dimensão processo, o planejamento, o monitoramento e a avaliação obtiveram implantação incipiente (42,9\%). Foram classificados como implantados o comando operacional e a comunicação de risco, que alcançaram cada um 85,7\%, e a pesquisa com $80 \%$ (Tabela 2).

O componente Vigilância da resposta à emergência em saúde pública foi classificado como implantado, nas dimensões estrutura $(81,9 \%)$ e processo $(80,6 \%)$. Sete dos dez itens avaliados foram considerados como implantados, com 100\% (recurso financeiro, normativas, análise de dados e divulgação de informações e medidas de controle e prevenção). Os recursos humanos $(69,2 \%)$, a estrutura física (75\%) e o processo de investigação $(62,5 \%)$ obtiveram classificação parcial, decorrente principalmente de questões relacionadas ao Cievs, como sua inexistência regional e o vínculo profissional precário de sua equipe, além de adversidades relacionadas ao laboratório, como baixa disponibilidade e demora na implantação do diagnóstico para detecção do ZIKV, incipiente diagnóstico diferencial e morosidade na emissão dos laudos (Tabela 2).

As dimensões estrutura e processo do componente Assistência alcançaram 66,7\% e 69,7\%, respectivamente, classificadas como implantação parcial. A implantação incipiente dos recursos humanos $(57,1 \%)$, a estrutura física $(57,1 \%)$ e os equipamentos $(50 \%)$ decorreram principalmente da inexperiência e do despreparo da gestão para resposta à emergência em saúde pública e à precária disponibilidade de serviços especializados nas macrorregiões afastadas da capital. Na dimensão processo, os cuidados da gestante com exantema e da criança com microcefalia apresentaram $60 \%$ e $73,9 \%$, respectivamente. Destaca-se a exígua celeridade na contratualização de serviços nas macrorregiões e a não constatação de monitoramento e avaliação das ações (Tabela 2).

\section{Tabela 1}

Grau de implantação (GI) segundo dimensão e componentes da resposta à emergência da microcefalia. Pernambuco, Brasil, $2015-2017$.

\begin{tabular}{|c|c|c|c|c|c|c|c|c|c|c|}
\hline \multirow[t]{3}{*}{ Componentes } & \multicolumn{3}{|c|}{ Estrutura } & \multicolumn{3}{|c|}{ Processo } & \multicolumn{3}{|c|}{ GI (\%) } & \multirow[t]{3}{*}{ Julgamento } \\
\hline & \multicolumn{2}{|c|}{ Pontuação } & \multirow[t]{2}{*}{ GI (\%) } & \multicolumn{2}{|c|}{ Pontuação } & \multirow[t]{2}{*}{ GI (\%) } & \multirow{2}{*}{$\begin{array}{l}\text { Estrutura } \\
(\mathrm{GI} * 3) / 10\end{array}$} & \multirow{2}{*}{$\begin{array}{l}\text { Processo } \\
(G \mid * 7) / 10\end{array}$} & \multirow[t]{2}{*}{ Total } & \\
\hline & Máxima & Alcançada & & Máxima & Alcançada & & & & & \\
\hline Gestão & 31,0 & 23,0 & 74,2 & 31,0 & 23,0 & 74,2 & 22,3 & 51,9 & 74,2 & Parcial \\
\hline Vigilância & 36,0 & 29,5 & 81,9 & 36,0 & 29,0 & 80,6 & 24,6 & 56,4 & 81,0 & Implantado \\
\hline Assistência & 33,0 & 22,0 & 66,7 & 33,0 & 23,0 & 69,7 & 20,0 & 48,8 & 68,8 & Parcial \\
\hline $\begin{array}{l}\text { Gl na emergência em } \\
\text { saúde pública }\end{array}$ & 100,0 & 74,5 & 74,5 & 100,0 & 75,0 & 75,0 & 22,4 & 52,5 & 74,9 & Parcial \\
\hline
\end{tabular}


Tabela 2

Grau de implantação (GI) dos itens segundo as dimensões e componentes da resposta à emergência da microcefalia. Pernambuco, Brasil, 2015-2017.

\begin{tabular}{|c|c|c|c|c|}
\hline \multirow[t]{2}{*}{ Dimensão } & \multicolumn{2}{|c|}{ Pontuação } & \multirow[t]{2}{*}{ GI (\%) } & \multirow[t]{2}{*}{ Julgamento } \\
\hline & Máxima & Alcançada & & \\
\hline \multicolumn{5}{|l|}{ Estrutura } \\
\hline Recursos humanos & 10,0 & 7,0 & 70,0 & Parcial \\
\hline Recursos financeiros & 8,0 & 6,0 & 75,0 & Parcial \\
\hline Recursos materiais & 1,0 & 1,0 & 100,0 & Implantado \\
\hline Estrutura física & 2,0 & 2,0 & 100,0 & Implantado \\
\hline Normativas & 7,0 & 4,0 & 57,1 & Incipiente \\
\hline Equipamentos & 3,0 & 3,0 & 100,0 & Implantado \\
\hline GI da estrutura da gestão & 31,0 & 23,0 & 74,2 & Parcial \\
\hline \multicolumn{5}{|l|}{ Processo } \\
\hline Comando operacional & 7,0 & 6,0 & 85,7 & Implantado \\
\hline Planejamento, monitoramento e avaliação & 7,0 & 3,0 & 42,9 & Incipiente \\
\hline Comunicação de risco & 7,0 & 6,0 & 85,7 & Implantado \\
\hline Pesquisa & 10,0 & 8,0 & 80,0 & Implantado \\
\hline GI do processo da gestão & 31,0 & 23,0 & 74,2 & Parcial \\
\hline \multicolumn{5}{|l|}{ Estrutura } \\
\hline Recursos humanos & 13,0 & 9,0 & 69,2 & Parcial \\
\hline Recursos financeiros & 2,0 & 2,0 & 100,0 & Implantado \\
\hline Recursos materiais & 6,0 & 5,0 & 83,3 & Implantado \\
\hline Estrutura física & 4,0 & 3,0 & 75,0 & Parcial \\
\hline Normativas & 6,0 & 6,0 & 100,0 & Implantado \\
\hline Equipamentos & 5,0 & 4,5 & 90,0 & Implantado \\
\hline GI da estrutura da vigilância & 36,0 & 29,5 & 81,9 & Implantado \\
\hline \multicolumn{5}{|l|}{ Processo } \\
\hline Detecção/Notificação & 8,0 & 7,0 & 87,5 & Implantado \\
\hline Investigação & 16,0 & 10,0 & 62,5 & Parcial \\
\hline Análise de dados e divulgação de informação & 8,0 & 8,0 & 100,0 & Implantado \\
\hline Medida de controle e prevenção & 4,0 & 4,0 & 100,0 & Implantado \\
\hline Gl do processo da vigilância & 36,0 & 29,0 & 80,6 & Implantado \\
\hline \multicolumn{5}{|l|}{ Estrutura } \\
\hline Recursos humanos & 7,0 & 4,0 & 57,1 & Incipiente \\
\hline Recursos financeiros & 2,0 & 2,0 & 100,0 & Implantado \\
\hline Recursos materiais & 2,0 & 2,0 & 100,0 & Implantado \\
\hline Estrutura física & 14,0 & 8,0 & 57,1 & Incipiente \\
\hline Normativas & 4,0 & 4,0 & 100,0 & Implantado \\
\hline Equipamentos & 4,0 & 2,0 & 50,0 & Incipiente \\
\hline GI da estrutura da assistência & 33,0 & 22,0 & 66,7 & Parcial \\
\hline \multicolumn{5}{|l|}{ Processo } \\
\hline Cuidado à gestante com exantema & 10,0 & 6,0 & 60,0 & Parcial \\
\hline Cuidado à criança com SCZV & 23,0 & 17,0 & 73,9 & Parcial \\
\hline Gl do processo da assistência & 33,0 & 23,0 & 69,7 & Parcial \\
\hline
\end{tabular}

SCZV: síndrome congênita do Zika vírus. 


\section{Discussão}

O GI da resposta de Pernambuco à emergência em saúde pública da microcefalia foi avaliado como parcial, com diferentes níveis de implantação entre os componentes. A Vigilância alcançou melhor nível quando comparada à Gestão e à Assistência, embora em todos existam lacunas em relação ao que está disposto nas normas.

O componente Gestão teve GI parcial em todas as suas dimensões. A boa compreensão dos agentes governamentais sobre gestão de crise, com estruturação do comando operacional, contribuiu positivamente, o que reforça que a apreensão da crise é essencial para o gerenciamento de processos em eventos complexos, de forma integral e integrada. Estudos mostram que primordialidade do planejamento prévio, conhecimento de causa e intersetorialidade no enfrentamento de situações problemáticas globais impõem o reforço às competências básicas dos envolvidos nas respostas à emergência em saúde pública 24.

A inexistência pregressa de plano para emergência em saúde pública pode ter contribuído para lacunas na preparação e resposta local. Pesquisa realizada no Reino Unido constatou a ineficiência dos planos locais governamentais para o enfrentamento à pandemia de H1N1, em 2009. O estudo concluiu que os planos representam apenas a intenção de ação e não garantem as diretrizes de gestão durante o evento, pois são construídos à luz de um futuro incerto, com relações de poderes voláteis e parcialmente congelados, o que dificulta a aplicabilidade na realidade 25 . Se essa situação ocorre com a existência de planos, pode ser pior na sua ausência.

Neste estudo, identificou-se que, apesar de o contingente técnico e financeiro ser restrito, a gestão teve capacidade adaptativa no reposicionamento de técnicos e na realocação orçamentária. A governança dos recursos financeiros e humanos é estruturante na gestão da emergência em saúde pública. Pesquisas mostram que as consequências da indefinição no financiamento público para ações emergenciais são particularmente descritas nas fases de preparação, principalmente nos treinamentos, exercícios e estabilidade funcional. $\mathrm{Na}$ fase de resposta, a incerteza e a demora no financiamento impactam a avaliação dos riscos e a oportunidade de controle do problema 24,26,27.

O gerenciamento da pesquisa influiu positivamente para o componente Gestão, tendo maior interlocução com a Vigilância e um distanciamento operacional com a Assistência. A identificação oportuna das potencialidades da colaboração científica foi firmada com a criação de um grupo multinacional, multi-institucional e transdisciplinar, com participação ativa e em igualdade de posição de pesquisadores. Pesquisa realizada em 2016 sobre questões éticas relacionadas à emergência da epidemia pelo ZIKV reafirmou a importância da cooperação entre os integrantes de uma equipe para alcançar os resultados almejados em uma emergência em saúde pública de importância internacional. A solução de problemas complexos, cujas causas são imbricadas e abstrusas, só pode ser compreendida em sua totalidade ao miscigenar conceitos de várias disciplinas 28,29,30.

Outra capacidade essencial para o gerenciamento é a comunicação de risco. A emergência em saúde pública de microcefalia gerou interesse midiático mundial e busca por informações pela sociedade civil, profissionais de saúde, cientistas e autoridades governamentais. A inexistência de um portavoz oficial não foi considerada um problema para interlocução da Secretaria de Saúde com a mídia, o que pode ser decorrente da não ocorrência de um campo de disputa atrelado ao cenário político local 31. Contudo, a pulverização de interlocutores acrescentou demanda para os profissionais nos níveis gerencial, técnico, clínico e científico. O esforço para esclarecer a população sobre as medidas adequadas é apontado como inibidor à propagação de notícias falsas, como visto em outras epidemias, e gera confiança nas ações governamentais 32. No Brasil, a comunicação também é uma forma de estimular a participação popular na efetivação do SUS. Ela contribui com a redução das desigualdades em saúde ao permitir que as pessoas possam ter informações para tomar decisões que vão repercutir na saúde individual e coletiva 31 .

A Gestão moldou-se aos acontecimentos, articulando e viabilizando ações diversas. A raridade e imprevisibilidade do evento dificultou a exploração das capacidades ou as adequações dos serviços, dada a necessidade de mudança nas respostas exercidas na rotina. De forma semelhante, Grisotti 2 aponta que uma das maiores dificuldades em casos de emergência em saúde pública de importância internacional reside em alterar suas respostas corriqueiras diante da necessidade de gerir ações em âmbito transnacional. Outro estudo 33 indica que as políticas em países de baixa e média renda encon- 
tram obstáculos à sua implementação, pelo fato de as pessoas tenderem a resistir às mudanças, por perturbarem as estruturas de poder e as maneiras de fazer as coisas.

O componente Vigilância alcançou o maior GI, provavelmente porque o Brasil cumpre a maioria dos requisitos do RSI (2005) com relação a estrutura, supervisão e procedimentos dispostos como capacidades básicas para vigilância 11. Primando pela "segurança em saúde global”, a OMS preconizou a formação de uma rede mundial de vigilância, estruturada no país como Cievs no nível federal, estadual e em alguns municípios. Em Pernambuco, o investimento no Cievs mostrou-se efetivo, dando condições para verificação, alerta, pronta resposta e monitoramento do evento 9 .

A resposta à epidemia de microcefalia mostrou a capacidade de Pernambuco de superar crises, evidenciada pela estabilidade dos serviços de vigilância, apesar da desigualdade social e econômica, agravado pela crise política nacional vigente desde 2016. O reconhecimento do papel assumido pelo estado foi evidenciado na literatura1, e pode ser argumentado pela busca de implementar as ações postas pelo RSI, investindo nas equipes envolvidas para que possam compreender, implementar e manter as ações, fato não observado na resposta à epidemia de Ebola na África. Outros autores 30,34 apontam que o descompromisso político e as desigualdades econômicas e sociais contribuem para o baixo investimento no fortalecimento das capacidades de vigilância, principalmente em países de baixa renda, diminuindo a envergadura dos sistemas de saúde para agir em situações críticas de danos e agravos à saúde.

Identificou-se nesta pesquisa a habilidade de o Cievs captar, compreender e produzir informações oportunas capazes de gerar ações correspondentes. A capacidade instalada do setor de vigilância no estado possibilitou que a informação produzida contribuísse com a ação de enfrentamento da microcefalia 9 . O uso de ferramentas tecnológicas para obtenção e consolidação dos dados agilizou a produção, análise e divulgação de informações. Essa é uma condição para a detecção, confirmação e resposta oportuna em situações críticas descritas por Steele et al. 34 em revisão sistemática sobre fatores que influenciam na resposta precoce a emergências.

As fragilidades na resposta da Vigilância se relacionaram à persistência de questões estruturais e de processo de trabalho. Pesquisa realizada entre trabalhadores de saúde, na China, corrobora esses achados ao mostrar que a rotatividade de profissionais fragiliza as ações e gera descontinuidade das atividades 35 .

Talvez o maior desafio dessa epidemia tenha sido o diagnóstico etiológico para o ZIKV. Os problemas estruturais identificados contribuíram para a delonga na investigação dos casos. Isso ilustra a falha na governança global que, segundo estudos, marginaliza o investimento na detecção, no tratamento e no controle de doenças infecciosas, e também limita a pesquisa, o desenvolvimento, a produção e a aplicação de novas tecnologias de saúde em contextos complexos de emergência 30,36.

A epidemia da microcefalia implicou enfrentar uma situação, mesmo diante da inexistência de evidências técnico-científicas que a respaldassem. Nessa circunstância, o estado produziu protocolos e normativas técnicas para vigilância e assistência, com base em conhecimento fragmentado ajustado a partir da geração de evidências no transcorrer da emergência em saúde pública. O estado contribuiu para a resposta de saúde no Brasil e no mundo, e foi reconhecido quanto aos aspectos de detecção, pronta resposta, integração e monitoramento 8,9,37.

Outro pilar da Vigilância é o controle da propagação do evento. Em Pernambuco, 81\% dos municípios são de pequeno porte e com rede de serviços de saúde precária. A frágil conjuntura local exigiu apoio para 33 municípios com alto risco de transmissão vetorial, com vistas à adoção de medidas de controle do Aedes. Envolver a gestão local nas decisões e implementação das atividades tem sido visto como essencial para a continuidade das ações e a preparação para situações futuras de resposta a crises 29,36 .

No RSI, a assistência à saúde restringe-se à prestação de ações locais e pontuais, com função complementar às atividades de vigilância ${ }^{17}$. No Brasil, a normatização implementada para ações assistenciais em emergência em saúde pública circunscreveu sua estruturação à esfera federal, com a criação da Força Nacional do SUS, serviço com ação restrita a momentos de desassistência 18.

No componente Assistência, as limitações da preparação gerencial e a sobrecarga nas unidades de referência foram amenizadas pelo engajamento dos profissionais de saúde. Contudo, esse atendimento reprimido às crianças e pessoas com deficiência e a escassez de recursos humanos são citados em 
estudos como fatores que precediam a emergência em saúde pública da microcefalia e que tensionaram o sistema de saúde na disponibilização de serviços que extrapolavam o limite operacional 13,38.

Apesar de as crianças com SCZV requererem atendimentos com maior complexidade, a estruturação dessa rede de serviços ocorreu de forma mais ágil e com prioridade quando comparada ao cuidado às gestantes com exantema. Ainda assim, a descentralização desses serviços para as macrorregiões foi limitada e fragmentada. Isso também foi constatado por Albuquerque e colaboradores, ao identificarem que o acesso aos cuidados de crianças com microcefalia ocorria de forma desigual em Pernambuco, devido à concentração de $75 \%$ dos serviços de reabilitação na região metropolitana 13 .

A prática de monitoramento e a avaliação das ações não foram constatadas no componente Assistência. O investimento nessas técnicas de gestão se faz necessário, uma vez que a disponibilidade de informações estratégicas, advindas das unidades de saúde, é fundamental para a organização, implementação e avaliação quantitativa e qualitativa dos cuidados e serviços. Sua importância está na contribuição para a avaliação do custo-efetividade das ações e consta nas recomendações do consenso sobre defeitos de nascimento para a América Latina e Caribe 39.

Neste estudo, limitações estruturais foram identificadas. Ainda assim, o uso do sistema público de saúde no Brasil tem sido relatado como mais amplo na oferta de cuidado à criança com microcefalia, quando comparado ao sistema privado 13. Contudo, a estruturação de sua continuidade deve ser alvo de políticas públicas com vistas à transposição das barreiras de acesso, à qualificação na prestação de cuidados e ao gerenciamento da crescente demanda de recursos médicos 14 .

Uma das limitações deste estudo foi a instabilidade do constructo e do conteúdo da intervenção, por se tratar de um evento inusitado, sobre o qual não havia conhecimento nem diretrizes específicas, que foram sendo elaboradas à medida que as evidências surgiam no curso da emergência em saúde pública de importância internacional. Para sobrepujar esses problemas e ampliar a robustez da avaliação, foram utilizadas múltiplas fontes de informação e realizada uma conferência de consenso com especialistas para referendar o modelo lógico da intervenção e a matriz de indicadores, de forma a subsidiar uma abordagem baseada na teoria e prática.

O GI da emergência em saúde pública relacionada à microcefalia no Estado de Pernambuco foi avaliado como implantação parcial. Embora existam hiatos entre o que é proposto nas normativas e o que foi observado em todos os componentes, a Vigilância teve melhor implantação relacionada à adesão precoce do Brasil aos protocolos de emergência em saúde pública e à experiência prévia dos profissionais em lidar com essas situações. Importa, portanto, investir nos outros dois componentes, Gestão e Assistência, principalmente no quesito recursos humanos e estrutura física, planejamento e avaliação, considerando a importância do pleno funcionamento do tripé Gestão, Vigilância e Assistência no enfrentamento oportuno de emergência em saúde pública. Permanece o desafio para a completa assimilação das normas propostas pelo RSI no cotidiano dos serviços, pelas equipes de saúde e, principalmente, por seus gestores.

Recomenda-se, para superar as insuficiências, fortalecer as estruturas dos serviços de resposta à emergência, aprimorar planos de ação integrados, implementar o processo da avaliação e criar condições para a governança do sistema de saúde. Tais iniciativas são imprescindíveis para a qualificação do sistema de saúde e a maior efetividade na resposta a situações emergenciais. 


\section{Colaboradores}

L. R. Aguiar, P. G. Frias, L. R. M. Quinino, D. B. Miranda-Filho contribuíram com as etapas de concepção do projeto, análise e interpretação dos dados, redação e revisão crítica do artigo, aprovação final da versão a ser publicada, e declaram serem responsáveis por todos os aspectos do trabalho, incluindo a garantia de sua precisão e integridade.

\section{Informações adicionais}

ORCID: Lucilene Rafael Aguiar (0000-0003-42860378); Paulo Germano de Frias (0000-0003-44978898); Louisiana Regadas de Macedo Quinino (0000-0002-7123-8089); Democrito de Barros Miranda-Filho (0000-0003-2537-1476).

\section{Referências}

1. Kluge H, Martín-Moreno JM, Emiroglu N, Rodier G, Kelley E, Vujnovic M, et al. Strengthening global health security by embedding the International Health Regulations requirements into national health systems. BMJ Glob Health 2018; 3 Suppl 1:e000656.

2. Grisotti MM. Governança em saúde global no contexto das doenças infecciosas emergentes. Civitas - Revista de Ciências Sociais 2016; 16:377-98.

3. Jee Y. WHO International Health Regulations Emergency Committee for the COVID-19 outbreak. Epidemiol Health 2020; 42:e2020013.

4. Soares de Araújo JS, Regis CT, Gomes RGS, Tavares TR, Rocha dos Santos C, Assunção PM, et al. Microcephaly in north-east Brazil: a retrospective study on neonates born between 2012 and 2015. Bull World Heal Organ 2016; 94:835-40.

5. Oliveira WK, França GVA, Carmo EH, Duncan BB, Kuchenbecker RS, Schmidt MI. Infectionrelated microcephaly after the 2015 and 2016 Zika virus outbreaks in Brazil: a surveillancebased analysis. Lancet 2017; 390:861-70.

6. Brito C. Zika virus: a new chapter in the history of medicine. Acta Med Port 2015; 28:67980.

7. Miranda-Filho DB, Martelli CMT, De Alencar Ximenes RA, Araújo TVB, Rocha MAW, Ramos RCF, et al. Initial description of the presumed congenital Zika syndrome. Am J Public Health 2016; 106:598-600.

8. Albuquerque MFPM, Souza WV, Araújo TVB, Braga MC, Miranda-Filho DB, Ximenes RAA, et al. Epidemia de microcefalia e vírus Zika: a construção do conhecimento em epidemiologia. Cad Saúde Pública 2018; 34:e00069018.

\section{Agradecimentos}

O presente estudo foi realizado com apoio da Coordenação de Aperfeiçoamento de Pessoal do Nível Superior (CAPES - código de financiamento 001).
9. Lima SS, Sivini MAVC, Oliveira RC, Azevedo BAS, Dias CC, Lopes ASA, et al. Estratégia de atuação do Cievs/Pernambuco na resposta à emergência da Síndrome Congênita associada à infecção pelo vírus Zika: uma ação integrativa. Rev Bras Saúde Mater Infant 2018; 18:443-8.

10. França GVA, Schuler-Faccini L, Oliveira WK, Henriques CMP, Carmo EH, Pedi VD, et al. Congenital Zika virus syndrome in Brazil: a case series of the first 1501 livebirths with complete investigation. Lancet 2016; 388:891-7.

11. Teixeira MG, Costa MCN, Souza LPF, Nascimento EMR, Barreto ML, Barbosa N, et al. Evaluation of Brazil's public health surveillance system within the context of the International Health Regulations (2005). Rev Panam Salud Pública 2012; 32:49-55.

12. Silva BCA, Andrade RS, Silva VS, Carneiro SRL, Dimech GS. Saúde Pernambuco - reflexões, evidências e experiências da vigilância em saúde. Pernambuco: Secretaria Executiva de Vigilância em Saúde/Secretaria Estadual de Saúde; 2019.

13. Albuquerque MSV, Lyra TM, Melo APL, Valongueiro SA, Araújo TVB, Pimentel C, et al. Access to healthcare for children with Congenital Zika Syndrome in Brazil: perspectives of mothers and health professionals. Health Policy Plan 2019; 34:499-507.

14. Lowe R, Barcellos C, Brasil P, Cruz OG, Honório NA, Kuper H, et al. The zika virus epidemic in brazil: from discovery to future implications. Int J Environ Res Public Health 2018; 15:96.

15. Donabedian A. Basic approaches to assessment: structure, process, and outcome. In: Explorations in quality assessment and monitoring. v. III. Ann Arbor: Health Administration Press; 1980. p. 77-125. 
16. Secretaria de Saúde de Pernambuco. Plano Estadual de Saúde 2016-2019. http://portal. saude.pe.gov.br/sites/portal.saude.pe.gov.br/ files/plano_estadual_de_saude_2016-2019. pdf (acessado em 11/Fev/2018).

17. World Health Organization. Resolutions and decisions 58.3 - revision of the International Health Regulations. http://www.who.int/ipcs/ publications/wha/ihr_resolution.pdf (acessado em 20/Mar/2018).

18. Brasil. Decreto no 7.616, de 17 de novembro de 2011. Dispõe sobre a declaração de Emergência em Saúde Pública de Importância $\mathrm{Na-}$ cional e institui a Força Nacional do Sistema Único de Saúde. Diário Oficial da União 2011; 18 nov.

19. Secretaria de Vigilância em Saúde, Ministério da Saúde. Plano de resposta às emergências em saúde pública. http://www.saude.gov.br/ima ges/pdf/2014/outubro/07/plano-de-respostaemergencias-saude-publica-2014.pdf (acessado em 11/Set/2018).

20. Secretaria de Saúde de Pernambuco; Secretaria de Vigilância em Saúde. Portaria no 493 de 6 de julho de 2009. Institui o Centro de Informações Emergenciais de Vigilância em Saúde. Diário Oficial do Estado de Pernambuco 2009; 7 jul.

21. Secretaria Executiva de Vigilância em Saúde; Secretaria de Saúde de Pernambuco. Protocolo Clínico e Epidemiológico para investigação de casos de microcefalia no estado de Pernambuco. Versão no 01. https://12ad4c92-89c74218-9e11-0ee136fa4b92.filesusr.com/ugd/ 3293a8_bdbc939959174a79941f197903 ad3bc9.pdf (acessado em 28/Fev/2018)

22. Secretaria Executiva de Vigilância em Saúde; Secretaria de Saúde de Pernambuco. Protocolo clínico e epidemiológico para investigação de microcefalia no estado de Pernambuco. Versão no 02 https://12ad4c92-89c7-4218-9e11-0ee 136fa4b92.filesusr.com/ugd/3293a8_f8b f59781b39477289c57c75e94a40cf.pdf (acessado em $28 / \mathrm{Fev} / 2018$ )

23. Figueirôa BQ, Frias PG, Vanderlei LCM, Vidal SA, Carvalho PI, Pereira CCB, et al. Avaliação da implantação do Sistema de Informações sobre Mortalidade no Estado de Pernambuco em 2012. Epidemiol Serv Saúde 2019; 28:e2018384.

24. Khan Y, Brown A, Shannon T, Gibson J, Généreux $\mathrm{M}$, Henry $\mathrm{B}$, et al. Public health emergency preparedness: a framework to promote resilience. BMC Public Health 2018; 18:1344.

25. Davis M, Flowers P, Stephenson N. We had to do what we thought was right at the time: Retrospective discourse on the 2009 H1N1 pandemic in the UK. Sociol Heal Illn 2014; 36:369-82.

26. Kinsman J, Angrén J, Elgh F, Furberg M, Mosquera PA, Otero-García L, et al. Preparedness and response against diseases with epidemic potential in the European Union: a qualitative case study of Middle East Respiratory Syndrome (MERS) and poliomyelitis in five member states. BMC Health Serv Res 2018; 18:528.
27. Bevc CA, Simon MC, Montoya TA, Horney JA. Institutional facilitators and barriers to local public health preparedness planning for vulnerable and at-risk populations. Public Health Rep 2014; 129 Suppl 4:35-41.

28. Ferguson GM, Fiese BH, Nelson MR, Meeks Gardner JM. Transdisciplinary team science for global health: case study of the JUS Media? Programme. Am Psychol 2019; 74:725-39.

29. Rego S, Palácios M, De A. Ética, saúde global e a infecção pelo vírus Zika: uma visão a partir do Brasil. Rev Bioét 2016; 24:430-4.

30. Heymann DL, Chen L, Takemi K, Fidler DP, Tappero JW, Thomas MJ, et al. Global health security: the wider lessons from the west African Ebola virus disease epidemic. Lancet 2015; 385:1884-901.

31. Lindenmeyer L, Martins CM. Comunicação e saúde nos manuais dos organismos internacionais para situações de emergência e desastre: intervenção e hegemonia. Interface (Botucatu) 2015; 19:299-310.

32. Sumo J, George G, Weah V, Skrip L, Rude JM, Clement P, et al. Risk communication during disease outbreak response in post-Ebola Liberia: experiences in Sinoe and Grand Kru counties. Pan Afr Med J 2019; 33 Suppl 2:4.

33. Campos PA, Reich MR. Political analysis for health policy implementation. Health Syst Reform 2019; 5:224-35.

34. Steele L, Orefuwa E, Dickmann P. Drivers of earlier infectious disease outbreak detection: a systematic literature review. Int J Infect Dis 2016; 53:15-20.

35. Zhang W, Meng H, Yang S, Liu D. The influence of professional identity, job satisfaction, and work engagement on turnover intention among township health inspectors in China. Int J Environ Res Public Health 2018 ; 15:988.

36. Ventura DFL. Do Ebola ao Zika: as emergências internacionais e a securização da saúde global. Cad Saúde Pública 2016; 32:e00033316.

37. Costa JMBS, Reis YAC, Cazarin G, Bezerra LCA, Silva IMS. Painel estadual de monitoramento da infecção pelo vírus zika e suas complicações: caracterização e uso pela vigilância em saúde. Saúde Debate 2017; 41(spe):316-28.

38. Moreira MCN, Nascimento M, Mendes CHF, Pinto M, Valongueiro S, Moreira MEL, et al. Emergency and permanence of the Zika virus epidemic: an agenda connecting research and policy. Cad Saúde Pública 2018; 34:e00075718.

39. Zarante I, Hurtado-Villa P, Walani SR, Kancherla V, López Camelo J, Giugliani R, et al. A consensus statement on birth defects surveillance, prevention, and care in Latin America and the Caribbean. Rev Panam Salud Pública 2019; 43:e2. 


\section{Abstract}

This study aimed to assess the degree of implementation of the response to the emergency of microcephaly associated with Zika virus in Pernambuco State, Brazil. This was a normative evaluative study conducted in the initial epicenter of the public health emergency of international concern, from October 2015 to July 2017. A logical model was produced for the intervention under analysis, with the components of Management, Surveillance, and Care in the dimensions of structure, process, and result, based on technical publications and institutional guidelines, in addition to a corresponding log frame of indicators for assessment. Data were collected through a questionnaire, direct observation, and consultation of official documents. The results showed partial implementation (74.9\%) of the response to the microcephaly emergency by the Pernambuco State Health Department, with the process dimension reaching $75 \%$ of the expected level and the structure dimension, $74.5 \%$. Surveillance was the only component that was assessed as implemented (81\%), although with a shortage of regional and laboratory investments, while Management (74.2\%) and Care (68.8\%) were partially implemented, with insufficiencies in items related to human resources and physical structure, planning, and evaluation. In conclusion, the response to the public health emergency of international concern involving microcephaly associated with the Zika virus was assessed as partially implemented, with different levels between the intervention's components, especially surveillance when compared to management and care. The shortcomings signal the need for investments to deal with future public health emergencies, with a view towards more timely and adequate interventions.

Health Evaluation; Emergency Plans; Microcephaly

\section{Resumen}

El objetivo de este estudio fue evaluar el grado de implantación de la respuesta a la emergencia de microcefalia, asociada al virus Zika, en Pernambuco, Brasil. Se trata de un estudio evaluativo normativo, realizado en el epicentro inicial de la emergencia en salud pública internacional, ocurrida entre octubre de 2015 y julio de 2017. Se elaboró un modelo lógico de la intervención, bajo el análisis que contenía los componentes Gestión, Vigilancia y Asistencia, en sus dimensiones de estructura, proceso y resultado, a partir de publicaciones técnicas y normativas institucionales, $y$ una matriz de indicadores correspondiente para el juicio. Se recogieron datos a partir de la aplicación del cuestionario, observación directa y consulta de documentos oficiales. Los resultados mostraron una implantación parcial $(74,9 \%)$ de la respuesta a la emergencia de microcefalia por la Secretaría Estatal de Salud, con la dimensión proceso alcanzando a un $75 \%$ de lo esperado y la estructura, un 74,5\%. La Vigilancia fue el único componente evaluado como implantado (81\%), aunque con carencia de inversiones regionales y de laboratorio, y la Gestión (74,2\%) y Asistencia (68,8\%), parcialmente implantadas, con insuficiencias en los requisitos referentes a recursos humanos y estructura física, planificación y evaluación. Se concluye que el grado de implantación de la respuesta a la emergencia en salud pública internacional de microcefalia, asociada al virus Zika, fue evaluado como implantación parcial, con diferentes niveles entre los componentes de la intervención, sobresaliendo la Vigilancia, en comparación con la Gestión y la Asistencia. Las inconformidades indican la necesidad de inversiones para enfrentar futuras emergencias en salud pública, con vista a intervenciones más oportunas y adecuadas.

Evaluación en Salud; Planens de Emergencia; Microcefalia
Recebido em 15/Set/2020

Versão final reapresentada em 11/Dez/2020

Aprovado em 17/Dez/2020 